\title{
Removal of Heavy Metals from Aqueous Solution by Zeolite in Competitive Sorption System
}

\author{
Sabry M. Shaheen, Aly S. Derbalah, and Farahat S. Moghanm
}

\begin{abstract}
In this study, the sorption behaviour of natural (clinoptilolite) zeolites with respect to cadmium (Cd), copper $(\mathrm{Cu})$, nickel ( $\mathrm{Ni})$, lead $(\mathrm{Pb})$ and zinc $(\mathrm{Zn})$ has been studied in order to consider its application to purity metal finishing wastewaters. The batch method has been employed, using competitive sorption system with metal concentrations in solution ranging from 50 to $300 \mathrm{mg} / \mathrm{l}$. The percentage sorption and distribution coefficients $\left(K_{\mathrm{d}}\right)$ were determined for the sorption system as a function of metal concentration. In addition lability of the sorbed metals was estimated by DTPA extraction following their sorption. The results showed that Freundlich model described satisfactorily sorption of all metals. Zeolite sorbed around 32, 75, 28, 99, and $59 \%$ of the added $\mathrm{Cd}, \mathrm{Cu}, \mathrm{Ni}, \mathrm{Pb}$ and $\mathrm{Zn}$ metal concentrations respectively. According to the percentage sorption and distribution coefficients values, the selectivity sequence of studied metals by zeolite can be given as $\mathbf{P b}>\mathbf{C u}>\mathrm{Zn}>\mathbf{C d}>$ Ni. About 57, 47, 78, 22, and $29 \%$ from the total sorbed Cd, $\mathrm{Cu}, \mathrm{Ni}, \mathrm{Pb}$ and $\mathrm{Zn}$ recovered by DTPA indicating that lability of the adsorbed $\mathrm{Ni}$ was higher than, $\mathrm{Cd}, \mathrm{Cu}, \mathrm{Zn}$, and $\mathrm{Pb}$ respectively. These results show that natural zeolites hold great potential to remove cationic heavy metal species from industrial wastewater.
\end{abstract}

Index Terms — Sorption, lability, heavy metals, zeolite.

\section{INTRODUCTION}

Many toxic heavy metals have been discharged into the environment as industrial wastes, causing serious soil and water pollution. Cadmium, $\mathrm{Cu}, \mathrm{Ni}, \mathrm{Pb}$ and $\mathrm{Zn}$ are especially common metals that tend to accumulate in organisms, causing numerous diseases and disorders. They are also common groundwater contaminants at industrial and military installations [1]. Numerous processes exist for removing dissolved heavy metals, including sorption, precipitation, phytoextraction, ultrafiltration, reverse osmosis, and electrodialysis [2], [3]. The use of alternative low-cost materials as potential sorbents for the removal of heavy metals has been emphasized recently.

Various treatment processes are available, among which sorption is considered to be cost-effective if low-cost sorbents such as zeolites are used [4]. Zeolites are naturally occurring hydrated aluminosilicate minerals. They belong to the class of minerals known as "tectosilicates." Most common natural zeolites are formed by alteration of glass-

Manuscript received May 13, 2012; revised July 9, 2012. This work was supported by the University of Kafrelsheikh, sector of postgraduate and research affairs, university research fund (Project No. KFUR03).

Sabry M. Shaheen is with the Dept. of Soil \& Water Sciences, Faculty of Agriculture, University of Kafrelsheikh, 33 516- Kafr El-Sheikh, Egypt (e-mail: smshaheen1973@yahoo.com).

Aly S. Derbalah is with the Department of Pesticides, Faculty of Agriculture, University of Kafrelsheikh, 33 516- Kafr El-Sheikh, Egypt (email: aliderbalah@yahoo.com) rich volcanic rocks (tuff) with fresh water in playa lakes or by seawater [5].

The structures of zeolites consist of three-dimensional frameworks of $\mathrm{SiO}_{4}$ and $\mathrm{AlO}_{4}$ tetrahedra. The aluminum ion is small enough to occupy the position in the center of the tetrahedron of four oxygen atoms, and the isomorphous replacement of $\mathrm{Si}^{4+}$ by $\mathrm{Al}^{3+}$ produces a negative charge in the lattice. The net negative charge is balanced by the exchangeable cation (sodium, potassium, or calcium). These cations are exchangeable with certain cations in solutions such as lead, cadmium, zinc, and manganese [6]. The fact that zeolite exchangeable ions are relatively innocuous (sodium, calcium, and potassium ions) makes them particularly suitable for removing undesirable heavy metal ions from industrial effluent waters. Clinoptilolite is the most abundant natural zeolite and has the chemical formula: $\mathrm{Na}_{0.1} \mathrm{~K}_{8.57} \mathrm{Ba}_{0.04}\left(\mathrm{Al}_{9.31} \mathrm{Si}_{26.83} \mathrm{O}_{72}\right) \cdot{ }_{19.56} \mathrm{H}_{2} \mathrm{O}$ [7].Its characteristic tabular morphology shows an open reticular structure of easy access, formed by open channels of 8- to 10-membered rings [8]. Considerable research has been conducted to characterize the chemical, surface, and sorption properties of clinoptilolite [9]. The sorption capacity of natural zeolite (clinoptilolite) for inorganic cations has been investigated by many authors [10]. The selectivity series of clinoptilolite in the sodium form was determined by Zamzow et al., as follows: $\mathrm{Pb}>\mathrm{Cd}>\mathrm{Cs}>\mathrm{Cu}>\mathrm{Co}>\mathrm{Cr}>\mathrm{Zn}>\mathrm{Ni}>\mathrm{Hg}$ [11]. Mier et al. [12] Studied the sorption of $\mathrm{Pb}^{2+}, \mathrm{Cu}^{2+}, \mathrm{Fe}^{3+}$, and $\mathrm{Cr}^{3+}$ on natural clinoptilolite and showed that equilibriumis favorable for $\mathrm{Pb}$, unfavourable for $\mathrm{Cu}$, and of sigmoid shape for $\mathrm{Cr}^{3+}$ and $\mathrm{Fe}^{3+}$. As seen from the literature review, zeolites can be used for the removal of some heavy metals from wastewater. The clinoptilolite samples from different regions show different behaviour in sorption processes. In this study, the sorption properties of the natural zeolite (Clinoptillolite, Western Anatolian) with respect to some heavy metal cations in solution were investigated.

Sorption of heavy metals can be described by a linear, Langmuir, or Freundlich sorption model [13]. The Freundlich equation is often useful for modeling sorption of metals onto solids with heterogeneous surfaces and has frequently proved superior to the Langmuir equation for cations or anions sorption [14]. Although, there is disagreement regarding the effectiveness of Langmuir and Freundlich models to interpret sorption of metal cations [15], some parameters of these models, such as maximum sorption quantity and the distribution coefficient are widely acceptable in characterizing metals sorption capacity of soils and other materials [16], [17]

Distribution coefficient is a useful parameter for comparing the sorptive capacity of different soils or materials for any particular ion, when they are measured under the same experimental conditions [18]. The mobility 
under the same experimental conditions [18]. The mobility of metals in the environment are directly related to their partitioning between solid and iquid phases [15] and, therefore, are directly related to their distribution coefficients, which indicate the capability of a sorpent to retain a solute and the extent of its movement to the liquid phase [19]

\section{MATERIALS AND METHODS}

\section{A. Zeolite Selection and Characterization}

Clinoptilolite zeolite selected from 'Beli Plast' mine (Bulgaria). Selected properties of zeolite are analyzed and presented in Table I.

TABLE I: SELECTED PROPERTIES OF STUDIED ZEOLITE

\begin{tabular}{lc}
\hline Properties & Concentrations \\
\hline Chemical composition, \% & 70.1 \\
$\mathrm{SiO}_{2}$ & 11.4 \\
$\mathrm{Al}_{2} \mathrm{O}_{3}$ & 3.30 \\
$\mathrm{~K}_{2} \mathrm{O}$ & 2.95 \\
$\mathrm{CaO}$ & 0.78 \\
$\mathrm{Fe}_{2} \mathrm{O}_{3}$ & 0.70 \\
$\mathrm{Na}_{2} \mathrm{O}$ & 0.37 \\
$\mathrm{MgO}_{\mathrm{TiO}}$ & 0.13 \\
$\left.\mathrm{Exchangeable} \mathrm{Cations,} \mathrm{(cmol(+)} \mathrm{kg}^{-1}\right)$ & \\
$\mathrm{Ca}^{++}$ & 92.6 \\
$\mathrm{Mg}^{++}$ & 3.21 \\
$\mathrm{Na}$ & 23.1 \\
$\mathrm{~K}^{+}$ & 87.5 \\
$\mathrm{DTPA}$-extractable heavy metals, $\mathrm{mgkg}^{-1}$ & \\
$\mathrm{Cd}$ & 0.018 \\
$\mathrm{Cr}$ & 0.110 \\
$\mathrm{Cu}$ & 1.192 \\
$\mathrm{Ni}$ & 0.168 \\
$\mathrm{~Pb}$ & 8.920 \\
$\mathrm{Zn}$ & 4.896 \\
\hline
\end{tabular}

\section{B. Sorption Experiment}

A batch equilibrium experiment was conducted using $\mathrm{Cd}$, $\mathrm{Cu}, \mathrm{Ni}, \mathrm{Pb}$ and $\mathrm{Zn}$ in a competitive sorption system with metal concentrations in solution ranging from 50 to 300 $\mathrm{mg} / \mathrm{l}$ from all metals studied as follows: $1000 \mathrm{mg} / \mathrm{l}$ stock solution contain all studied metals have been prepared. Two $\mathrm{g}$ of zeolite samples were equilibrated with $20 \mathrm{~mL}$ of $0.01 \mathrm{M}$ $\mathrm{CaCL}_{2}$ solutions containing 50, 100, 150, 200, 250, and 300 $\mathrm{mg} / \mathrm{l}$ as a chloride salts in $50-\mathrm{mL}$ centrifuge tubes (preweighed) for $24 \mathrm{~h}$ on a reciprocating shaker at room temperature. Some drops of toluene were added to suppress microbial activity. After equilibration the samples were centrifuged and the supernatant was filtered through a Whitman No. 42 filter paper. Two replicates were used for collecting each data point. Metals concentrations in the supernatant were measured by atomic absorption spectrometry (Varian, SpectrAA-400 Plus, Australia). The amount of metals sorbed was calculated as the difference between the initial and final concentration.

Metals sorption data were fitted to Freundlich equation using the formula:

$$
q=k_{f} c^{n}
$$

where: $q$ is the sorbed metal amount in $\mathrm{mg} \mathrm{kg}^{-1} ; \boldsymbol{c}$ is the equilibrium solution concentration in $\mathrm{mg} / \mathrm{l}$. From this equation, the following sorption parameters were determined: $k_{f}$, which represents the metal sorbed at $\mathrm{c}=1$ $\mathrm{mg} / \mathrm{l}, n$ which is an empirical parameter expressing the metal sorption intensity. To fit the data, the model was linearized by using the logarithmic transformation resulting in the predictive equation $\log (q)=\log \left(K_{f}\right)+n \log (c)$. The linearized model fitted to each soil using analysis of covariance to estimate $\log \left(K_{f}\right)$ and $n$ and test if the $\log \left(K_{f}\right)$ and $n$ coefficients differed across the tested treatments. Estimates of $K_{f}$ were obtained using exp $\left(\log \left(K_{f}\right)\right)$. The distribution coefficient $\left(K_{\mathrm{d}}\right)$ values were calculated according to Anderson and Christensen, and Gomes et al. [20], [21] by using the formula:

$$
\text { Distribution coefficient }\left(K_{\mathrm{d}}\right)=q / c=k_{f} c^{n} / c=k_{f} c^{n-1}
$$

where $K_{d}$ was estimated using the estimates of $k_{f}$ and $n$ obtained as described above. Linear contrasts in the analysis of covariance model were used to test if $K_{d}$ values differed across each metal. The fit of the models were assessed using root mean square error and $R^{2}$ to evaluate the proportion of total variability explained by the model. The Proc GLM procedure in the SAS software package was for computation (SAS Institute, 2003).

\section{Lability of Sorbed metals}

Lability of sorbed metals was evaluated at the end of sorption experiment by DTPA extraction [22]. A 10-mL DTPA solution was added to each centrifuge tube containing metals-sorbed samples from the sorption experiment. Then the tubes were shaken for $120 \mathrm{~min}$ on a reciprocating shaker to extract the sorped metals, centrifuged, and the supernatant solutions were filtered and analyzed for $\mathrm{Cd}, \mathrm{Cu}, \mathrm{Ni}, \mathrm{Pb}$ and $\mathrm{Zn}$ content by atomic absorption spectrometry (Varian, SpectrAA-400 Plus, Australia). The amounts of $\mathrm{Cd}, \mathrm{Cu}, \mathrm{Ni}, \mathrm{Pb}$ and $\mathrm{Zn}$ extracted by DTPA at the end of sorption experiment were designated as the portion of sorbed metals retained in the labile pool, whereas the metals un-extractable by DTPA was attributed to zeolite $\mathrm{Cd}, \mathrm{Cu}, \mathrm{Ni}, \mathrm{Pb}$ and $\mathrm{Zn}$ in the non-labile pool.

\section{RESULTS AND DISCUSSIONS}

\section{A. Properties of Studied Zeolites}

A chemical analysis of the treated zeolite is presented in Table 1 . This study showed that natural zeolite contained a complement of exchangeable sodium, potassium, and calcium ions. The zeolite contained high percentage of $\mathrm{SiO}_{2}$, followed by $\mathrm{Al}_{2} \mathrm{O}_{3}, \mathrm{~K}_{2} \mathrm{O}, \mathrm{CaO}$, and negligible percentage of $\mathrm{Fe}_{2} \mathrm{O}_{3}, \mathrm{TiO}_{2}, \mathrm{MgO}$, and $\mathrm{Na}_{2} \mathrm{O}$, A description of the methods used to estimate zeolite composition along with some additional data on the chemical properties of the zeolite from the same mine can be found elsewhere [23]. Also, the zeolite contained high amounts of DTPA-extractable $\mathrm{Pb}$ and $\mathrm{Zn}$ respectively, while the concentrations of other metals were very low. Calcium and potassium were the dominant exchangeable cations while magnesium was the lowest one, (Table I). 


\section{B. Sorption of $\mathrm{Cd}, \mathrm{Cu}, \mathrm{Ni}, \mathrm{Pb}$ and $\mathrm{Zn}$ Metals on Natural Zeolite}

The sorption of $\mathrm{Cd}, \mathrm{Cu}, \mathrm{Ni}, \mathrm{Pb}$ and $\mathrm{Zn}$ onto natural zeolite as a function of their concentrations was studied at lab temperature by varying the metal concentration from 50 to $300 \mathrm{mg} / \mathrm{l}$ using competitive sorption system while keeping all other parameters constant. The results are shown in Table II \& III and Fig. 1 \& 2.

TABLE II: FREUNDLICH CONSTANTS $\left(K_{F \text { And }} N\right)$, MEAN VALUES OF DistRIBUTION COEFFICIENTS $\left(K_{\mathrm{D}}\right)$ AND MEAN VALUES OF METAL SORPTION PERCENT FOR THE METALS STUDIED BY ZEOLITE.

\begin{tabular}{cccccc}
\hline Metals & $\mathrm{n}$ & $K_{\mathrm{f}} l \mathrm{~kg}^{-1}$ & $K_{\mathrm{d}} l \mathrm{~kg}^{-1}$ & Metal Sorption,\% & $\mathrm{R}^{2}$ \\
\hline $\mathrm{Cd}$ & 0.29 & 117.0 & 5.34 & 31.5 & 0.99 \\
$\mathrm{Cu}$ & 0.29 & 406.7 & 68.31 & 74.9 & 0.93 \\
$\mathrm{Ni}$ & 0.34 & 77.34 & 4.05 & 27.5 & 0.99 \\
$\mathrm{~Pb}$ & 0.75 & 2194.3 & 2535.7 & 99.6 & 0.84 \\
$\mathrm{Zn}$ & 0.44 & 143.2 & 17.05 & 59.2 & 0.93 \\
\hline
\end{tabular}

TABLE III: THE DisTRIBUTION COEFFICIENT, $K_{D}\left(\mathrm{~L} \mathrm{KG}^{-1}\right)$ CALCULATED FOR EACH ADDED METAL CONCENTRATION AND $K_{D \text { MEDIUM }}$ FOR THE STUDIED METALS SORBED BY ZEOLITE.

\begin{tabular}{cccccc}
\hline $\begin{array}{c}\text { Initial Conc., } \\
\mathrm{mg} / \mathrm{l}\end{array}$ & $\mathrm{Cd}$ & $\mathrm{Cu}$ & $\mathrm{Ni}$ & $\mathrm{Pb}$ & $\mathrm{Zn}$ \\
\hline 50 & 13.09 & 266.6 & 8.83 & 3135.0 & 38.7 \\
100 & 6.22 & 53.3 & 4.85 & 2940.7 & 19.5 \\
150 & 4.32 & 36.6 & 3.49 & 2709.7 & 14.4 \\
200 & 3.33 & 23.8 & 2.77 & 2434.5 & 11.9 \\
250 & 2.76 & 18.0 & 2.32 & 2162.6 & 10.1 \\
300 & 2.35 & 11.6 & 2.02 & 1831.6 & 7.8 \\
$K_{\mathrm{d} \text { medium }}$ & 5.34 & 68.31 & 4.05 & 2535.70 & 17.05 \\
\hline
\end{tabular}

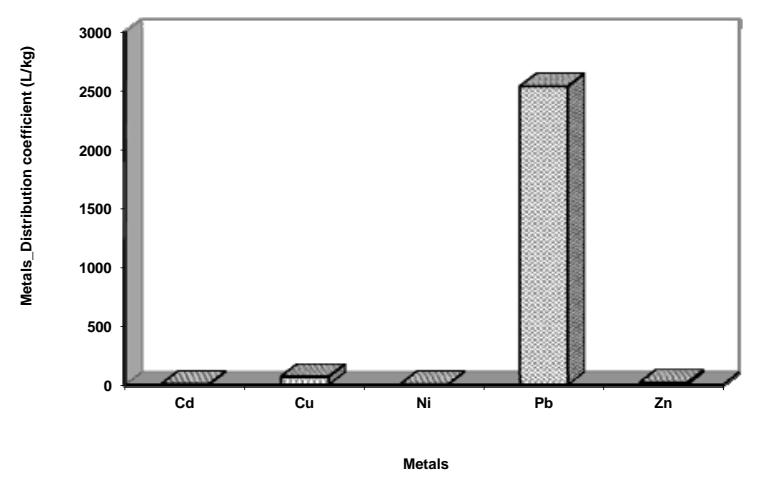

Fig. 1. Mean values of distribution coefficients $\left(K_{\mathrm{d}}\right)$ of metal sorption by zeolite

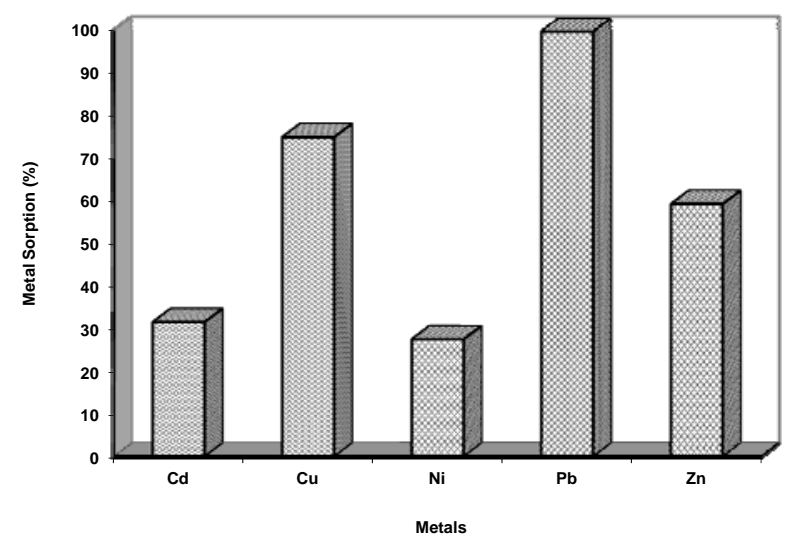

Fig. 2. Mean values of metals sorption percent by zeolite

Freundlich model described very well all metals sorption since $R^{2}$ values were found to be higher than 0.84 . The effectiveness of Freundlich equation in describing metal sorption was reported also by others [24]-[26].

The distribution coefficient $\left(K_{d}\right)$ is a useful index for comparing the sorptive capacities of different soils or materials for a particular ion under the same experimental conditions. It is defined as the ratio of the metal concentration in the solid phase to that in the equilibrium solution after a specified reaction time [18], [20]. Such coefficient represents the net result of all the various processes by which metal ions can be transferred between soil and solution, and are satisfactory for comparing the behaviour of different soils with respect to a given cation under fixed conditions. It is especially useful when the irregularity of empirical sorption and/or desorption isotherms hampers or prevents the fitting of simple empirical curves or theoretical models such as the Freundlich and Langmuir isotherms, as is often the case when the presence of more than one metal results in competition for sorption sites. A high $K_{d}$ value indicates high metal retention by the solid phase through chemical reactions, leading to low metal bioavailability. Similarly, a low $K_{\mathrm{d}}$ value indicates that a high metal amount remains in the solution [20], [21], [24]-[27]. Therefore, a further analysis of the obtained data based on the distribution coefficients was done. The distribution coefficient $\left(K_{d}\right)$ was calculated over the whole range of the added concentrations of studied metals. Also, the sorption selectivity sequence of the studied metals by the zeolite has been established at $K_{\mathrm{d}}$ medium values to obtain one comparable value for each metal and each soil [16], [24], [25], [28] as shown in Table 3.

Table III illustrates $K_{\mathrm{d}}$ as a function of metal ions concentrations. The data of Table 3 show that the percent of total sorbed $\mathrm{Cd}, \mathrm{Cu}, \mathrm{Ni}, \mathrm{Pb}$ and $\mathrm{Zn}$ decreased with increasing the initial metals concentration, as suggested by the decrease of $K_{\mathrm{d}}$ values with the increase metals addition. The $K_{d}$ values increase with the decreasing concentration of metal ions. In other words, the $K_{\mathrm{d}}$ values increase as dilution of metal ions in solution proceeds. This indicates that changes occur in the nature of the sites involved in the sorption process, depending upon the metal concentration as it was suggested by Shaheen [16]. The higher $K_{d}$ value obtained in the experiment with lower metal concentrations is associated with the sorption sites of high selectivity, which have relatively strong bonding energies. Otherwise, heavy metal sorption becomes unspecific at higher metal concentrations, when the specific bonding sites become increasingly occupied, resulting in lower $K_{\mathrm{d}}$ values [16], [28], [29].

Increasing rates of $\mathrm{Cd}, \mathrm{Cu}, \mathrm{Ni}, \mathrm{Pb}$ and $\mathrm{Zn}$ addition to the zeolite may result in saturation of metals sorption sites, thereby decreasing the sorption capacity. In this respect, Saha et al [29] explained that at low metal concentrations metals are mainly sorbed onto specific sorption sites, while cat higher metal concentrations soils lose some of their ability to bind heavy metals as sorption overlap, becoming thus less specific for a particular metal. This in turn induces a reduction in metal sorption. Also, these results indicate that energetically less favorable sites become involved with increasing metal concentrations in the aqueous solution. The heavy metal sorption is attributed to different mechanisms of ion-exchange processes as well as to the adsorption 
process. During the ion-exchange process, metal ions had to move through the pores of the zeolite mass, but also through channels of the lattice, and they had to replace exchangeable cations (mainly sodium and calcium). Diffusion was faster through the pores and was retarded when the ions moved through the smaller diameter channels. In this case the metal ion uptake could mainly be attributed to ion-exchange reactions in the microporous minerals of the zeolite samples.

\section{Distribution Coefficient Values and Selectivity Sequences of $\mathrm{Cd}, \mathrm{Cu}, \mathrm{Ni}, \mathrm{Pb}$ and $\mathrm{Zn}$ by the Studied Zeolite}

According to the percentage sorption and distribution coefficients values, the selectivity sequence of studied metals by zeolite can be given as $\mathrm{Pb}>\mathrm{Cu}>\mathrm{Zn}>\mathrm{Cd}>\mathrm{Ni}$. Lead presented the highest $K_{d}$ values followed by $\mathrm{Cu}, \mathrm{Zn}$, $\mathrm{Cd}$ and $\mathrm{Ni}$, showing that it was retained stronger than the other tested metals especially $\mathrm{Cd}$ and $\mathrm{Ni}$ (Table $2 \& 3$ ). These data demonstrated the preference of zeolite for $\mathrm{Pb}$ compared to $\mathrm{Cd}$ (Fig $1 \& 2$ ). This is usually attributed to differences in metal characteristics and resultant affinity for sorption sites [30]. For example, the hydrated radius of $\mathrm{Pb}^{2+}$ is smaller than that of $\mathrm{Cd}^{2+}\left(\mathrm{Pb}^{2+}=0.401 \mathrm{~nm} ; \mathrm{Cd}^{2+}=0.426\right.$ $\mathrm{nm}$; [31], favouring coulombic interactions of $\mathrm{Pb}$ with exchange sites. Furthermore, $\mathrm{Pb}$ has a greater affinity for most functional groups in organic matter including carboxylic and phenolic groups, which are hard Lewis bases. This is mainly attributed to the differences in chemical properties between the two metals. Lead as a harder Lewis acid $\left(\mathrm{Pb}^{2+}\right.$ is a borderline Lewis acid while $\mathrm{Cd}^{2+}$ is a soft Lewis acid), has a higher electronegativity (2.33 and 1.69 for $\mathrm{Pb}$ and $\mathrm{Cd}$, respectively) and lower $\mathrm{p} K_{H}$ (negative log of hydrolysis constant; 7.71 and 10.1 for $\mathrm{Pb}$ and $\mathrm{Cd}$, respectively) than $\mathrm{Cd}$. These factors favour $\mathrm{Pb}$ for innersphere surface sorption/complexation reactions compared to Cd. Lead $\left(\mathrm{Pb}^{2+}\right)$ also has 2 valence electrons in its $6 \mathrm{~s}$ atomic orbital (and empty p orbitals of only slightly higher energy), which can form, depending on the $\mathrm{Pb}-\mathrm{O}$ symmetry, molecular orbitals with $\mathrm{O} 2 \mathrm{p}$ atomic orbitals originating from an oxide surface. This orbital overlap stabilizes the $\mathrm{Pb}$ O complex. On the other hand, $\mathrm{Cd}^{2+}$ has a filled $4 \mathrm{~d}$ valence atomic orbital, which participates minimally in electron sharing with $\mathrm{O} 2 \mathrm{p}$ atomic orbitals from oxide surfaces.

The previously mentioned support that the sorption preference exhibited by these soils for $\mathrm{Pb}$ over the $\mathrm{Cd}$ may be attributed to: (i) the greater hydrolysis constant (ii) the higher atomic weight, (iii) the higher ionic radius, and subsequently smaller hydrated radius, and (iv) its larger Misono softness value, making it a better candidate than other metals for electrostatic and inner-sphere surface complexation reactions.

The $K_{\mathrm{d}}$ values indicate that $\mathrm{Cu}$ adsorption was higher than Zn sorption (Table $2 \& 3$ ). The preferential retention of $\mathrm{Cu}$ by the soil is, however, inconsistent with cation exchange theory that predicts selective adsorption on the basis of crystalline radii in a given ionic charge [13]- [14]. The ionic radius of $\mathrm{Zn}$ is $0.74 \mathrm{~A}^{\circ}$, whereas that of $\mathrm{Cu}$ is $0.72 \mathrm{~A}^{\circ}$. Thus, according to cation exchange theory, a preferential retention of $\mathrm{Zn}$ against $\mathrm{Cu}$ should be expected. The preferential retention of $\mathrm{Cu}$ against $\mathrm{Zn}$ recorded in this study may be attributed to three factors that which favor $\mathrm{Cu}$ sorption: electronegativity, softness parameter, and first hydrolysis constant. According to [32], selective metal retention can be explained by the differences in electronegativity, which, in this case, is higher for $\mathrm{Cu}$ (2.0) than $\mathrm{Zn}$ (1.6). However, other investigators pointed out that the first hydrolysis constant is most predictive for metal adsorption selectivity by specimen Fe oxides and soil colloids [33]. The first hydrolysis constant (pK1) for $\mathrm{Cu}$ varies between 7.3 and 8.0, whereas the $\mathrm{pK} 1$ for $\mathrm{Zn}$ ranges from 9.0 to 9.4 [33]. Furthermore, Misono et al derived a softness parameter to predict metal affinity sequences or preferential retention of metals by soil colloids. The Misono softness parameter is an index of the tendency of a metal to form covalent bonds with colloids [14], calculated from its ionic charge and the ionization potential (which is greater for $\mathrm{Cu}$ than $\mathrm{Zn}$ ). Thus, the preferential retention of $\mathrm{Cu}$ to $\mathrm{Zn}$ is in apparent agreement with differences in electronegativity, first hydrolysis constants, and the softness parameter.

Also, data shwed that, $K_{d}$ values of $\mathrm{Zn}$ were higher than $\mathrm{Cd}$ indicating that this was retained by the zeolite stronger than Cd (Figure 3). These data demonstrated the preference of zeolite for $\mathrm{Zn}$ compared to $\mathrm{Cd}$ under the competitive sorption system. This order indicates the higher tendency of $\mathrm{Cd}$ to remain in solution compared to zinc. This is usually attributed to differences in metal characteristics and resultant affinity for sorption sites which could be summarized as follow: Ionic radii Cd $(0.97 \AA)>\mathrm{Zn}(0.74 \AA)$ [34]; Atomic weight $\mathrm{Cd}$ (112.41) > Zn (65.38) [34]; Electronegativity $\mathrm{Cd}(1.7)>\mathrm{Zn}$ (1.6) [22] Hydrolysis constant $\mathrm{Zn} \mathrm{(9.0)>Cd} \mathrm{(10.1)} \mathrm{[35]} \mathrm{and} \mathrm{softness} \mathrm{Cd}$ (3.04) > Zn (2.34) [36].

The sorption isotherms indicated that Cd sorption for the zeolite was larger than $\mathrm{Ni}$. This result may be related to their ionic radii and chemical properties. The electronegativity (X) values are 1.46 and 1.75 and their radii are 0.098 and 0.069 $\mathrm{nm}$ for $\mathrm{Cd}$ and $\mathrm{Ni}$, respectively. The average electric dipole polarizabilities of $\mathrm{Cd}$ and $\mathrm{Ni}$ atoms are 7.2 and $6.8 \times 10^{-24}$ $\mathrm{cm}^{3}$, respectively [37].

\section{Lability of the Adsorbed $\mathrm{Cd}$ and $\mathrm{Pb}$}

The sorbed $\mathrm{Cd}, \mathrm{Cu}, \mathrm{Ni}, \mathrm{Pb}$ and $\mathrm{Zn}$ were partitioned into labile and non-labile pools distinguished by extracting with DTPA at the end of sorption experiment. The amount of labile $\mathrm{Cd}, \mathrm{Cu}, \mathrm{Ni}, \mathrm{Pb}$ and $\mathrm{Zn}$ as a mean values differed among the tested metals. Generally, on average, about 57, $47,78,22$, and $29 \%$ from the total sorbed $\mathrm{Cd}, \mathrm{Cu}, \mathrm{Ni}, \mathrm{Pb}$ and $\mathrm{Zn}$ recovered by DTPA indicating that lability of the adsorbed $\mathrm{Ni}$ was higher than, $\mathrm{Cd}, \mathrm{Cu}, \mathrm{Zn}$, and $\mathrm{Pb}$ respectively (Fig. 3).

These data indicate that the lability of $\mathrm{Ni}$, and $\mathrm{Cd}$ was the highest while lability of $\mathrm{Pb}$ was the lowest one between the studied metals. Therefore, $\mathrm{Ni}$ and $\mathrm{Cd}$ may pose more threats to the water contamination than $\mathrm{Pb}$ and $\mathrm{Zn}$. In this respect, Appel and $\mathrm{Ma}$ reported that, $\mathrm{Pb}$ demonstrated a higher affinity for materials sorption sites relative to $\mathrm{Ni}$ and $\mathrm{Cd}$. The former metal also confirmed its ability to take part in inner-sphere surface reactions, rendering it much less bioavailable and mobile in the environment, compared with $\mathrm{Ni}$ and $\mathrm{Cd}[30]$.

These data indicate that the lability of $\mathrm{Ni}$, and $\mathrm{Cd}$ was the highest while lability of $\mathrm{Pb}$ was the lowest one between the studied metals. Therefore, $\mathrm{Ni}$ and $\mathrm{Cd}$ may pose more threats 
to the water contamination than $\mathrm{Pb}$ and $\mathrm{Zn}$. In this respect, Appel and $\mathrm{Ma}$ reported that, $\mathrm{Pb}$ demonstrated a higher affinity for materials sorption sites relative to $\mathrm{Ni}$ and $\mathrm{Cd}$. The former metal also confirmed its ability to take part in inner-sphere surface reactions, rendering it much less bioavailable and mobile in the environment, compared with $\mathrm{Ni}$ and $\mathrm{Cd}[30]$.

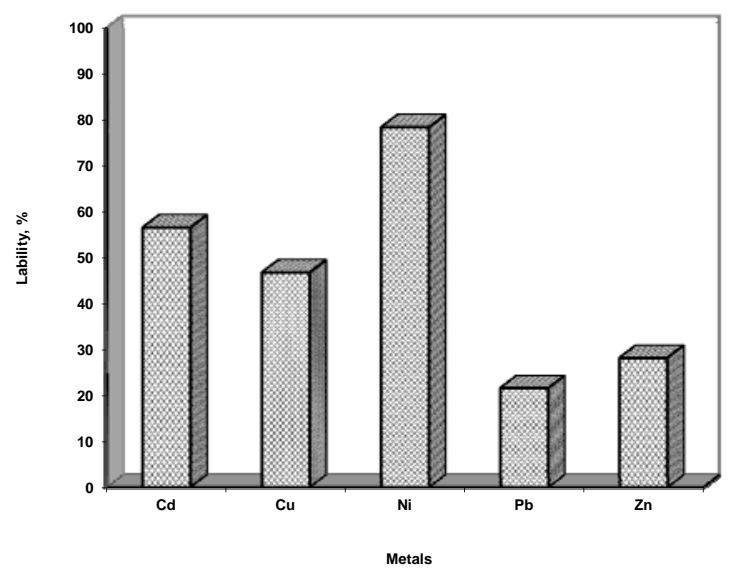

Fig. 3. Average percentage of labile forms of total sorbed metals by zeolite

\section{CONCLUSION}

In this study, competitive sorption characteristics and lability of the sorbed $\mathrm{Cd}, \mathrm{Cu}, \mathrm{Ni}, \mathrm{Pb}$ and $\mathrm{Zn}$ by zeolite were assessed at varying metal concentrations. Freundlich model described well all the studied metals sorption. Apparently due to Pb's chemical characteristics (relatively high electronegativity, lower $\mathrm{p} K_{H}$, small hydrated radius and electronic structure), this metal was sorbed stronger than other studied metals showing thus lower lability posing thus less threat to ground water systems compared to the other tested metals.

These results show that natural zeolite can be used effectively for the removal of metal cations from wastewater. This naturally occurring material provides a substitute for the use of other materials as adsorbent due to its availability and its low cost.

\section{ACKNOWLEDGMENT}

The authors thanks the financial supports providing from university of Kafrelsheikh, sector of postgraduate and research affairs, university research fund (Project No. KFUR03) in 2010.

\section{REFERENCES}

[1] A. Kabata-Pendias. "Trace elements in soils and plants." 4 nd ed. CRC Press, Boca Raton, FL, 2011. pp. 5-33.

[2] S. S. Ahluwalia, and D. Goyal. "Microbial and plant derived biomass for removal of heavy metals from wastewater". Bioresource Technology. vol. 98, Issue 12, pp. 2243-2257, September 2007.

[3] Babel, S.; T. A. Kurniawan, (2003) Low-cost adsorbents for heavy metals uptake from contaminated water: a review, J. Hazard. Mater. 97 219-243.

[4] S. E. Bailey, T. J. Olin, R. M. Bricka, and D. D. Adrian. "A review of potentially low-cost sorbents for heavy metals". Water Research. vol. 33 (11), pp. 2469-2479. August 1999.

[5] E. Erdem, N. Karapinar, and R. Donat. "The removal of heavy metal cations by natural zeolites". Journal of Colloid and Interface Science. vol. 280, pp. 309-314, September 2004.
[6] R. M. Barer, "Zeolites and clay minerals as sorbent and molecular sieves," Academic Press, New York, 1987.

[7] G. O. Brunner. "Quantitative zeolite topology, can help to recognize erroneous structures and to plan syntheses", Zeolites. vol. 13, Issue 2, pp. 88-91, February 1993.

[8] K. D. Mondale, R.M. Carland, F.F. Aplan. "The comparative ion exchange capacities of natural sedimentary and synthetic zeolites". Minerals Engineering, vol. 8, Issues 4-5, PP. 535-548, April-May 1995.

[9] A. C. Fyfe, H. Strobl, G. T. Kokotailo, C. T. Pasztor, G. E. Barlow, and S. Bradley. "Correlations between lattice structures of zeolites and their ${ }^{29}$ Si MAS n.m.r. spectra: zeolites KZ-2, ZSM-12, and Beta". Zeolites, vol. 8, Issue 2, pp. 132-136, March 1988,

[10] M. S Joshi, and P Mohan Rao. "Cation sieve properties of natural heulandite". Journal of Colloid and Interface Science. vol. 95, Issue 1, pp. 131-134, September 1983

[11] M. J. Zamzow, B. R. Eichbaum, K. R. Sandgren, D. E. Shanks, "Removal of heavy metals and other cations from wastewater using zeolites". Separation science and technology. vol. 25 (13-15), pp. 1555-1569, October, 1990.

[12] M. V. Mier, R. L. Callejas, R. Gehr, B. E. J. Cisneros, and P. J.J Alvarez. "Heavy metal removal with mexican clinoptilolite: multicomponent ionic exchange". Water Research, vol. 35, Issue 2, pp. 373-378, February 2001.

[13] G. Sposito, The Chemistry of Soils. Oxford University Press, New York, 1989, pp. 51-78.

[14] G. Sposito, "Derivation of the Freundlich equation for ion exchange in soils." Soil Science Society of America Journal, vol. 44, pp. 652654, June1980.

[15] D. L.Sparks, Environmental Soil Chemistry. Academic Press, New York, 1995.pp. 45-49.

[16] S. M. Shaheen, "Sorption and lability of cadmium and lead in different soils from Egypt and Greece.” Geoderma, vol. 153, pp. 6168, October, 2009.

[17] N. T. Basta, and M. A. Tabatabai, "Effect of cropping systems on sorption of metals by soils: III. Competitive sorption". Soil Science, vol. 153, pp. 331-337, April,1992a.

[18] B. J. Alloway, "Soil processes and the behavior of metals. in: Heavy Metals in Soils, Alloway, B.J. (Ed.),." Blackie Academic \& Professional, London, 1995, pp. 11-37.

[19] M. R. Reddy, and S.J. Dunn, "Distribution coefficient for Nickel and Zinc in soils", Environmental Pollution, vol. 11, pp.303-313, Jan. 1986.

[20] P. R. Anderson, and T. H. Christensen, "Distribution coefficients of $\mathrm{Cd}, \mathrm{Co}, \mathrm{Ni}$ and $\mathrm{Zn}$ in soils." J. Soil Science, vol. 39, pp.15-22, April, 1988.

[21] P. C. Gomes , M. P. F. Fontes, A. G. Da Silva, E. S. Mendonça, and R.A. Netto, "Selectivity sequence and competitive sorption of heavy metals by Brazilian soils.' Soil Sci. Soc. Am. J., vol. 65, pp. 11151121, October, 2001

[22] W. L. Lindsay, and W. A Norvell,. "Development of a DTPA soil test for zinc, iron, manganese and copper”. Soil Sci. Soc. Am. J., vol. 42, pp. 421-428, June 1978.

[23] Yu. I. Tarasevich, M.B. Kardashova, V.E. Polyakov, "Selectivity of ion exchange on clinoptilolite." Kolloid-Z, vol. 59 (6), pp. 813-818, July, 1997.

[24] S. M. Shaheen, C. D. Tsadilas, Th. Mitsibonas, and M. Tzouvalekas, "Distribution coefficient of copper in different soils from Egypt and Greece." Communication in Soil Science and Plant Analyses, vol. 40, pp.121-133, Jan. 2009.

[25] S. M. Shaheen, and C. D. Tsadilas, "Sorption of cadmium and lead by acidic Alfisols as influenced by fly ash and sewage sludge application. Pedosphere." vol. 20, no 4. pp. 436-445, August 2010.

[26] C. D. Tsadilas, S. M. Shaheen, V. Dimitrios Gizas; Samaras and Hu. Zhenqi," Influence of fly ash application on Copper and Zinc sorption by acidic soil amended with biosolids." Communication in Soil Science and Plant Analyses, vol..40, pp. 273-284, Jan. 2009.

[27] E. F. Covelo, F.A. Vega, and M.L. Andrade, "Competitive sorption and desorption of heavy metals by individual soil components." $J$. Hazard. Mater. vol. 140, pp. 308-315, Feb. 2007.

[28] S. M. Shaheen, C. D. Tsadilas and K. M. Eskridge. "Effect of common ions on phosphorus sorption and lability in Greek Alfisols with different pH'. Soil Science. vol. 174 (1), pp. 21-26, Jan. 2009.

[29] U.K. Saha, S. Taniguuchi, and K. Sakurai, "Simultaneous sorption of cadmium, zinc, and lead on hydroxyaluminum- and hydroxyaluminosilicate- montmorillonite complexes." Soil Sci. Soc. Am. J., vol. 66, pp.117-128, Jan. 2002.

[30] C. Appel, and L. Q. Ma, "Concentration, pH, and surface charge effects on cadmium and lead sorption in three tropical soils." $J$. Environ. Qual, vol. 31, pp. 581-589, April 2002. 
[31] E. R. Nightingale, "Phenomenological theory of ion solution. Effective radii of hydrated cations." J. Phys. Chem., vol. 63, pp. $1381-1387,1959$.

[32] M. B. McBride, Environmental Chemistry of Soils. Oxford Univ. Press, New York, 1994.

[33] A. Abd-Elfaltah, and K. Wada. "Adsorption of lead, copper, zinc, cobalt and cadmium by soils that differ in cation exchange materials." J. Soil Sci. Vol. 32, pp. 271-283, 1981.

[34] K. W. Whitten, K. D. Gailey, General Chemistry. Saunders College Publishing, New York, 1981.

[35] C. F. Baes, R.E. Mesmer, The Hydrolysis of Cations. New York, John Wiley and Sons, 1976.

[36] M. Misono, E. Ochiai, Y. Saito, Y. Yoneda, "A new dual parameter scale for the strength of Lewis acids and bases with the evaluation of their softness." J. Inorg. Nucl. Chem. vol. 29, pp. 2685-2691, 1967.

[37] C. Liu, T. Chang, M. Wang, and C. Huang, "Transport of cadmium, nickel, and zinc in Taoyuan red soil using one-dimensional convective-dispersive model." Geoderma, vol. 131 (1-2), pp.181-189, March 2006

[38] C. Appel, L. Q. Ma, R.D. Rhue, and W. Reve, "Sequential sorption of lead and cadmium in three tropical soils." Environmental pollution, vol.155, pp. 132-140, September, 2008.

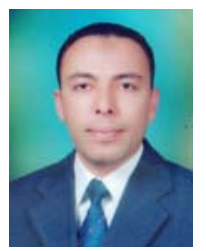

Sabry M. Shaheen was born at El-Behera, Egypt on August 28,1973. Ph.D. Kafr El-Sheikh Faculty of Agriculture, Tanta University, Egypt, February, 2005.

$\mathrm{He}$ is not required for the military, Visiting Researcher, May to November, 2012, Institute of Soil Engineering, Water \& Waste Management, Wuppertal University, Germany. Associate Professor, May 24, 2010 - Present, Department of Soil \& Water Sciences, Faculty of Agriculture, Kafrelsheikh University, Egypt. Assistant Professor, March, 2005 to May, 2010, Department of Soil \& Water Sciences, Faculty of Agriculture, Kafrelsheikh University, Egypt. Visiting Researcher, November, 2008 to May, 2009, ISMC, NAGREF,, Greece. Visiting Researcher, November 15, 2005 to November 7, 2006, ISMC, NAGREF,
Greece. Assistant Lecturer, December 18, 1999 to March 28, 2005, Faculty of Agriculture, Kafrelsheikh University, Egypt. Demonstrator, November 15, 1995 to December 17, 1999, Faculty of Agriculture, Kafrelsheikh University, Egypt.

He has published 11 paper in international journals. His research interests is Geochemistry of trace elements - Remediation of trace elements polluted soils and waters - Waste management- Chemistry of soil phosphorus.

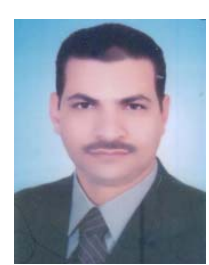

Aly S. Derbalah was at Kafr-el-zayat Gharbia, Egypt 23/07/1972. Ph.D. Hiroshima Univ, Hiroshima, Japan, February, 2004.

$\mathrm{He}$ is not required for the military, Associate Professor, January 2010- till now, Department of Pesticides, Faculty of Agriculture, Kafrelsheikh University, Egypt. Assistant Professor, 2004-2009, Department of Pesticides, Faculty of Agriculture, Kafrelsheikh University, Egypt. Assistant Lecturer, 1999 -2004, Department of Pesticides, Faculty of Agriculture, Kafrelsheikh University, Egypt. Demonstrator, 1994 -1999, Department of Pesticides, Faculty of Agriculture, Kafrelsheikh University, Egypt.

He has Published 12 paper in international journals. His research interests are Analysis, fate and remediation technologies of Pesticide residues in different environmental matrixes.

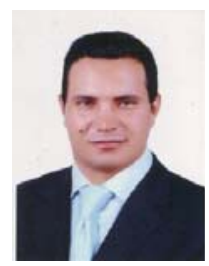

Farahat S. Moghanm was born at Kafr El-Sheikh, Egypt - 20/1/1976. Ph.D. in the field of the soil pedology (2009), Russia, Saint-Petersburg State Agrarian University.

He is not required for the military, 1- Demonstrato in soil dept. 1999-2003. 2- Assistant Lecturer, 2003 2009. 3- Research associate at Russia, Saint-Petersburg State Agrarian University 4- Assistant Professor, soil dept., Fac. of Agric., Kafr El-Sheikh Univ, 2010 -

Present.

He has Published 5 papers in national and international journals and conferences. His rsresearch interests is Pedology (Remote sensing and GIS). 